\title{
Pediatric Isolated Trachea Rupture Treated with a Conservative Approach
}

İ Akdulum ${ }^{1}$, M Öztürk ${ }^{2}$, N Dağ ${ }^{1}$, A Siğırc1 ${ }^{1}$

\begin{abstract}
Tracheobronchial rupture as a result of blunt thoracic trauma is extremely rare in children; it is a life-threatening event, as it progresses rapidly and causes respiratory problems. The causes of non-penetrating tracheobronchial injury include blunt cervical trauma, endotracheal intubation, and other iatrogenic reasons.

This paper presents the clinical and radiological results of a pediatric patient who developed an isolated tracheal rupture following blunt thoracic trauma.
\end{abstract}

Keywords: thoracic injuries, trachea, rupture, child

From: ${ }^{1}$ Department of Radiology, Inonu University School of Medicine, Malatya, Turkey. ${ }^{2}$ Diyarbakır Children's Hospital, Diyarbakır, Turkey.

Correspondence: Dr M Ozturk. Diyarbakır Children's Hospital, 21100, Diyarbakır, Turkey. Email: drmehmet3438@hotmail.com 


\section{INTRODUCTION}

The majority of tracheal ruptures occur following blunt trauma, constituting $1-2 \%$ of thoracic trauma and mortality rates of between $9-30 \%$ (1). Isolated tracheal rupture is extremely rare, and diagnosing it quickly is important for treatment and prognosis. Physical examination and imaging methods such as direct radiography and computed tomography (CT) are used in its diagnosis $(2,3)$. Although the standard treatment method is surgical, in recent studies, a conservative approach has been recommended, especially for children $(4,5)$. This paper presents the clinical and radiological results of an isolated tracheal rupture that developed following blunt thoracic trauma in a pediatric patient who recovered with conservative treatment.

\section{CASE REPORT}

An eight-year-old girl was brought into the emergency room complaining of respiratory difficulties that had suddenly developed following a fall from a bicycle. The physical examination revealed a respiratory problem and crepitation consistent with subcutaneous emphysema in the neck.

On the posteroanterior (PA) and lateral pulmonary radiograph, widespread free air lucency was observed subcutaneously in the neck and thorax as well as in the paratracheal soft tissue (Figure 1. a, b). 


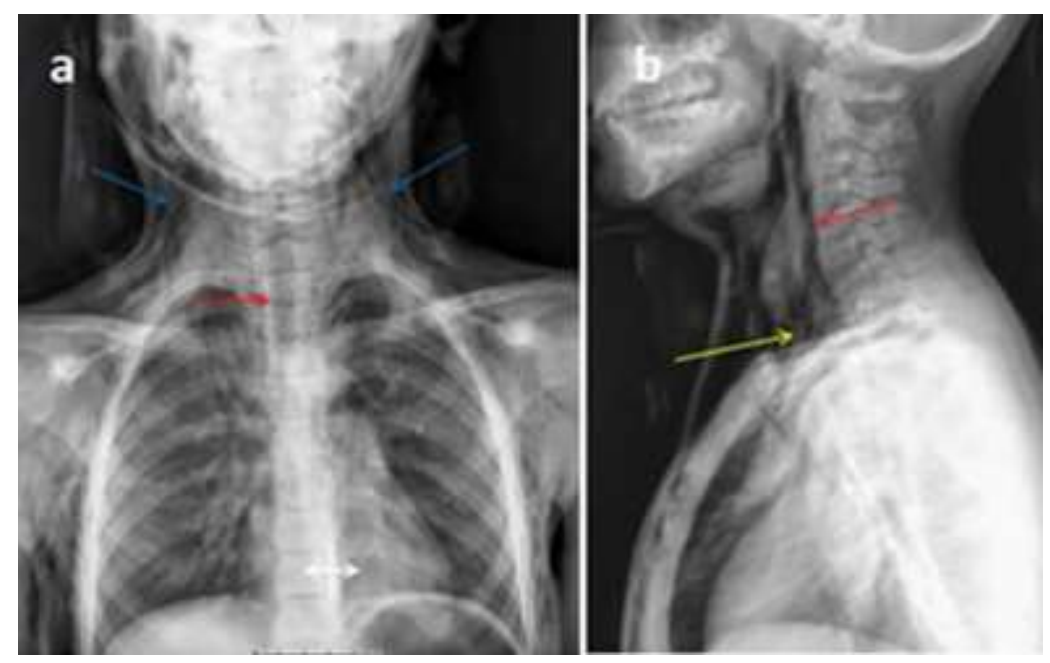

Fig. $1 \mathrm{a}, \mathrm{b}$ ) Posteroanterior (a) and lateral (b) pulmonary radiographs showing widespread free air lucency in the subcutaneous soft tissue of the neck and thorax (blue arrows) and in the soft tissue of the paratracheal area (yellow arrow). Trachea (red arrow).

On the thoracic axial, coronal, and sagittal multiplanar reformatted CT images, areas of free air density were seen around the trachea in the neck, in the soft tissue, and in the mediastinum, a defect consistent with a $2.5 \mathrm{~mm}$ width rupture in the posterior of the trachea at the level of the first thoracic vertebra and a line of air density extending to the surrounding soft tissue (Figure 2. a, b, c).
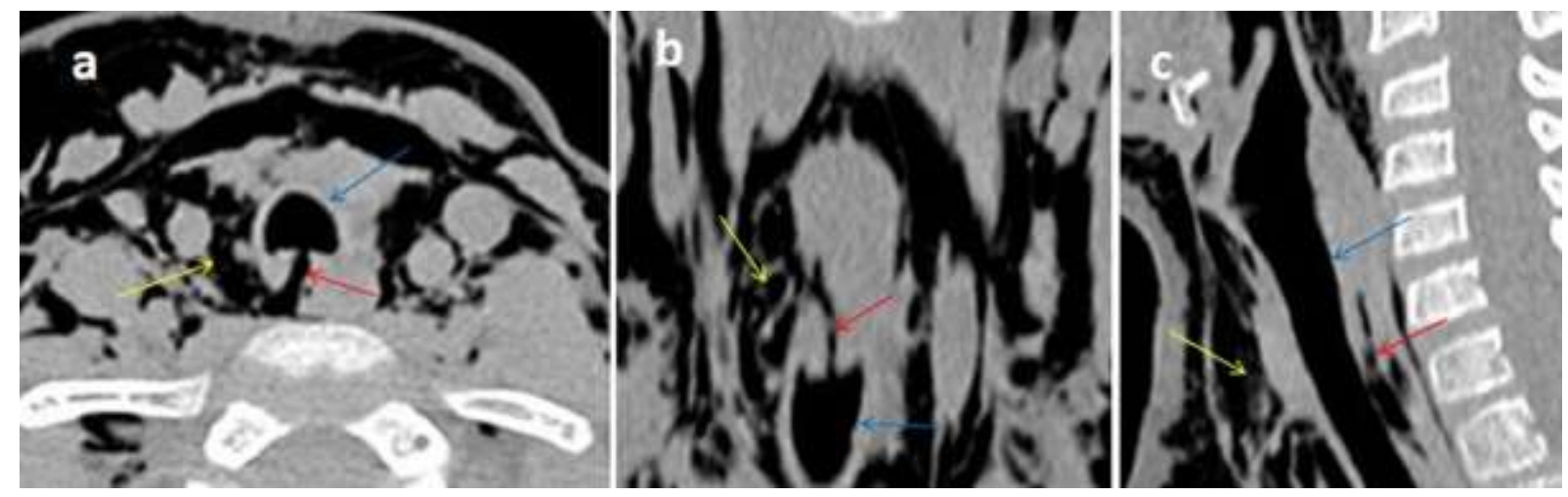

Fig 2. a, b, c) Thoracic CT multiplanar reformatted images: axial (a), coronal (b), and sagittal (c). Areas of free air density around the trachea in the neck, in the soft tissue, and in the mediastinum (yellow arrow). A defect consistent with rupture in the posterior of the trachea at the level of the first thoracic vertebra and an air density line extending to the surrounding soft tissue (red arrow). Trachea (blue arrow). 
The patient was monitored conservatively in the intensive care unit. After one week, the general status of the patient had improved and the radiographs were normal (Figure 3).
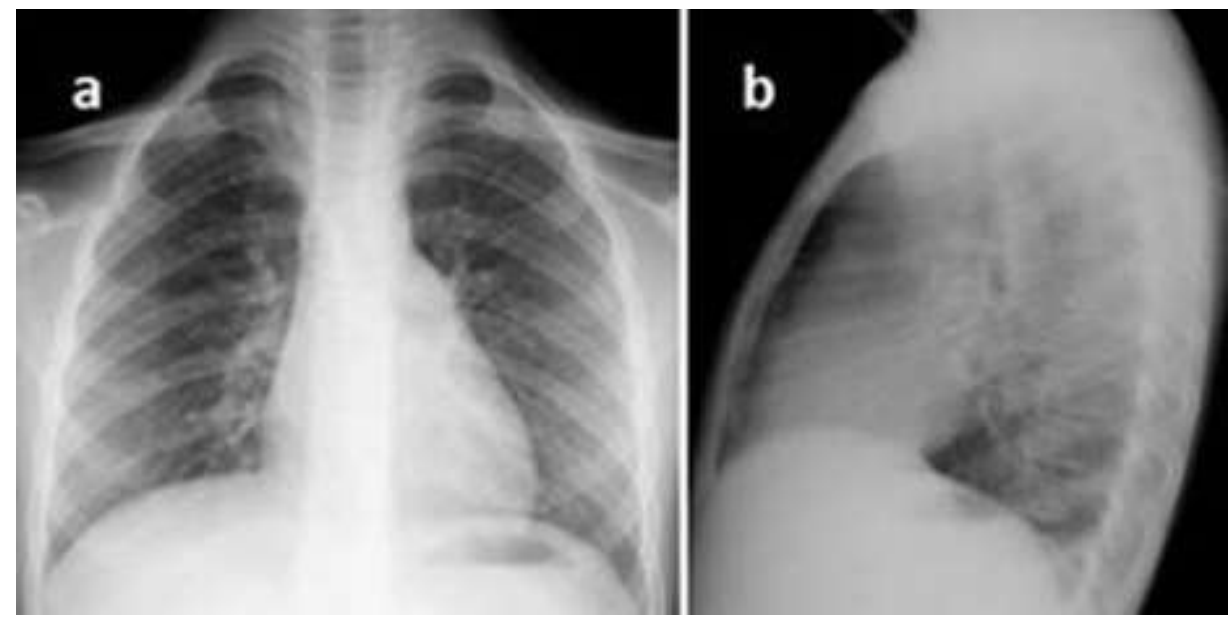

Fig. 3: Follow-up pulmonary radiographs after one week. No emphysema or pneumomediastinum observed on posteroanterior (a) or lateral (b) images.

\section{DISCUSSION}

As the trachea is in close proximity to the mandible, sternum, and vertebral column, it is rarely affected in trauma. Cartilage provides the trachea with support, movement, and an elastic structure in addition to stability. Due to the increase in traffic accidents, an increase in the rates of tracheobronchial injury following blunt trauma has been observed. Ruptures in the cervical section of the trachea have been reported in children as a result of accidents on bicycles and other similar vehicles (5).

The first clinical signs of tracheal injury may be non-specific, such as shortness of breath, coughing, hemoptysis, and cyanosis. Subcutaneous emphysema, pneumomediastinum, and pneumothorax together with severe respiratory problems should arouse high clinical 
suspicion (8). In the current case, the physical examination determined severe respiratory problems together with subcutaneous widespread crepitations in the neck and thorax.

In tracheobronchial injuries, the most common findings on pulmonary radiographs are the observation of pneumothorax, pneumomediastinum, and free air subcutaneously and in the deep soft tissue planes (7). Bronchoscopy is the gold standard for definitive diagnosis of tracheobronchial injuries (8). Three-dimensional $\mathrm{CT}$, which is a rapid and non-invasive method, and virtual bronchoscopy are extremely useful in showing the location, size, and extent of the rupture and accompanying findings as well as in the follow-up after treatment (9). In the current case, the level, size, and extent of the rupture were clearly determined on multiplanar reformatted images.

Surgery is the standard treatment for tracheal ruptures (10); however, in cases where the general condition is stable, and if pulmonary expansion can be provided with tube thoracostomy in small tracheal tears, a conservative approach is preferred (5). In the current case, as the rupture was small, and apart from respiratory problems there were no other findings, the patient was monitored conservatively with an endotracheal tube for one week. On the follow-up radiographs, no emphysema or pneumomediastinum was observed.

In conclusion, fine-slice $\mathrm{CT}$ and multiplanar reformatted images provided useful information for diagnosing an isolated tracheal rupture. In cases of a small tear with a good general condition, a conservative approach should be considered. 


\section{REFERENCES}

1. Huh J, Milliken JC, Chen JC: Management of tracheobronchial injuries following blunt and penetrating trauma. Am Surg 1997;63:896-9.

2. Chen JD, Shanmuganathan K, Mirvis SE, Killeen KL, Dutton RP. Using CT to diagnose tracheal rupture. AJR Am J Roentgenol 2001;176:1273-80.

3. Unger JM1, Schuchmann GG, Grossman JE, Pellett JR. Tears of the trachea and main bronchi caused by blunt trauma: radiologic findings. AJR Am J Roentgenol $1989 ; 153: 1175-80$.

4. Gómez-Caro A, Ausín P, Moradiellos FJ, Díaz-Hellín V, Larrú Larrú E, Pérez JA, et al. Role of conservative medical management of tracheobronchial injuries. J Trauma 2006; 61:1426-35.

5. Wood JW, Thornton B, Brown CS, McLevy JD, Thompson JW. Traumatic tracheal injury in children: a case series supporting conservative management. Int J Pediatr Otorhinolaryngol. 2015; 79:716-20.

6. Feat S, Le Clech G, Riffaud L, Godey B Complete cervical tracheal rupture in children after closed trauma. J Pediatr Surg 2002; 37: E39.

7. Narci H, Gündüz K, Yandi M. Isolated tracheal rupture caused by blunt trauma and the importance of early diagnosis: a case report. Eur J Emerg Med 2004; 11:217-9.

8. Ishibashi $\mathrm{H}$, Ohta $\mathrm{S}$, Hirose $\mathrm{M}$, Akimoto T. Blunt tracheal transection and long tear in posterior membranous trachea. Eur J Cardiothorac Surg 2006; 30:945-7.

9. Le Guen M, Beigelman C, Bouhemad B, Wenjïe Y, Marmion F, Rouby JJ. Chest computed tomography with multiplanar reformatted images for diagnosing traumatic bronchial rupture: a case report. Crit Care. 2007; 11:94. 
Akdulum et al

10. Gómez-Caro A, Ausín P, Moradiellos FJ, Díaz-Hellín V, Larrú, E, Pérez JA, et al. Role of conservative medical management of tracheobronchial injuries. J Trauma $2006 ; 61: 1426-35$. 